ISBN 978-981-14-1455-8

Proceedings of 2019 the 9th International Workshop on Computer Science and Engineering

WCSE 2019 SPRING

Yangon, Myanmar, February 27-March 1, 2019, pp. 198-202

doi:10.18178/wcse.2019.03.034

\title{
Flood Prediction System by using Markov Chain
}

\author{
Phyo Pa Pa Tun ${ }^{1+}$ and Myint Myint Sein ${ }^{2}$ \\ Geographic Information System (GIS Lab), University of Computer Studies, Yangon (UCSY) \\ phyopapatun@ucsy.edu.mm, myintucsy@gmail.com
}

\begin{abstract}
This study is tried to predict flood conditions for Mone Dam, Myanmar. The method of this system is based on Markov Chain to know about the flood in the study region. Flooding is one that the most hit disaster among the natural disasters. It extremely affected on environment, people and animals. People cannot elude from strike of flood but they can prepare from hit of the flood by predicting it. This system aims to predict the conditions of flood in Mone area in Myanmar. Markov Chain can be used to predict flood conditions in this system and input data as water level (Reservoir Level (RL)) combining with weather data from dark sky API. Th is system uses two-state and three-state Markov Chain and the output will be show the conditions of flood according to their facts as non-flood, flood and severe flood.
\end{abstract}

Keywords: Markov Chain, flood prediction, weather API, reservoir level, water level, Mone dam

\section{Introduction}

Water covered on the land that is not normally inundation is called flood. Myanmar meets flood in 2015 and later years. The main factor of occurring flood in Myanmar is monsoon rain, heavy rain and storm. Myanmar is weak to control from natural disasters and it is needed to develop a prediction system to protect from strike of flood. Dams are important for our humans' society because people need to store water for electricity and growing farm using irrigation water. However, it may be caused immediately flood in that region when the dam overflow water or dam break. Flooding and landslide are commonly occurs in rainy season when receive rainfall between mid-May and October. There are three waves a year that are generally happen flood in Myanmar with biggest hit arrive in August because monsoon rain arrive as peak at that time. This paper proposed the flood prediction system of Mone dam area in Myanmar. It will provide to know about the conditions of flood for people in that region and prepare to protect from flood.

Jayashree [3], it presented a method for design process of the system based on model-driven approach. In this system, some nodes set across the river to get real-time data. This system forecasts the flood conditions by us ing multiple linear regression models that can get speedy and accurate computation. This system has some weakness that is needed to apply various types of sensor and parameter. Therefore, it may cause highcost and complicated computation.

Yapo[4], it proposed the new method of stream flow forecasting model based on Markov Chain model for flood forecasting. This paper described three types of flood forecast: the maximum probable event forecast, the regression for recast, and threshold forecast. It does not need to know the exact value of stream flow for transition probability. However, stream flow data are not easy to get in some basin.

R.Kavitha [5], it proposed new Geo-Algorithm for mobile weather forecast during the cyclone disaster in location based on GIS. Service provider API service used to collect the Geospatial data in real time. In GoeAlgorithm, mobile users can find the near cities to know the weather changes by selecting locations via Google map based on latitude and longitude. This system accuracy is more precise and reduces processing

\footnotetext{
+ Corresponding author. Tel.: + 95-9-401537069; fax: +95-1-610633.

E-mail address: phyopapatun@ucsy.edu.mm.
} 
time than other systems. But it forecast only for cyclone and not forecast for storm and various natural disasters.

T.C. Cham [6], it described to know about the flood that it is calculated flood inundation depth and estimated the flood volume. This system is needed to study the time series changes of flood storage volume in midstream for disaster mitigation and to minimize the flood risk at downstream. This system calculates the depth of water from water surface in raster and DEM data. So, the accuracy of this system may be lack because some images will be missing.

This work proposed flood prediction system based on Markov chain for Mone dam area in Myanmar. The main reason of this system is to develop a prediction system for flood because Myanmar is weak to protect disasters and need to controlled natural disasters. The proposed system is to predict flood conditions in Mone dam by monitoring weather conditions and water level. It aims to help people from damage of flood.

\section{Study Area}

Mone dam is built on Mone creek basin and it is situated on Middle-West region of Myanmar. Kyee-On Kyee-Wa dam and Mone dam are closely related on that basin. If both dams were flood at the same time, it is very dangerous situation on people who live in Mone region. Mon creek flows begin from Mt. Khaw $\mathrm{Nu}$ Thon and it is the biggest sub-creek of Ayeyarwaddy river that it flows across Sidoktaya Township. Fig 1(a) shows the map of location of Mone dam and Fig 1(b) shows the map of inflow water of Mone dam respectively. The mountain of this region is very height and steep slope that these remain 30,000 feet above sea level. The transportation is difficult to communicate with other towns and it has only one main road to go to Salin (far from about 37 miles). People who live in Pwintbyu and Sidoktaya are very dangerous region when the dams will break or overflow water.

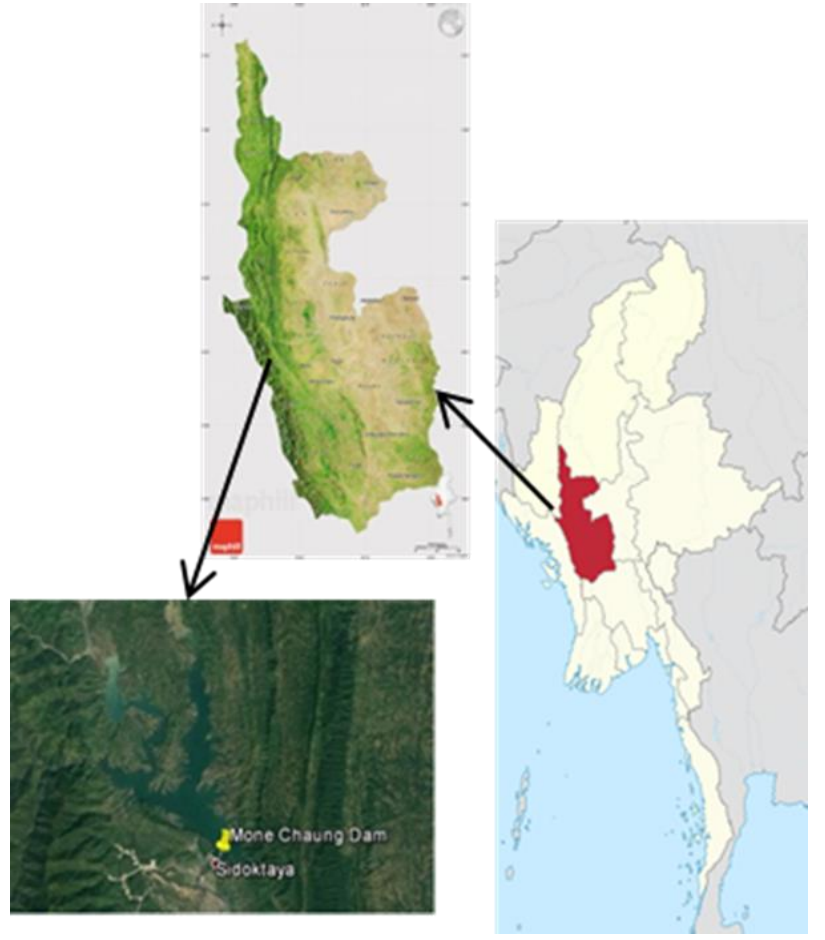

(a)

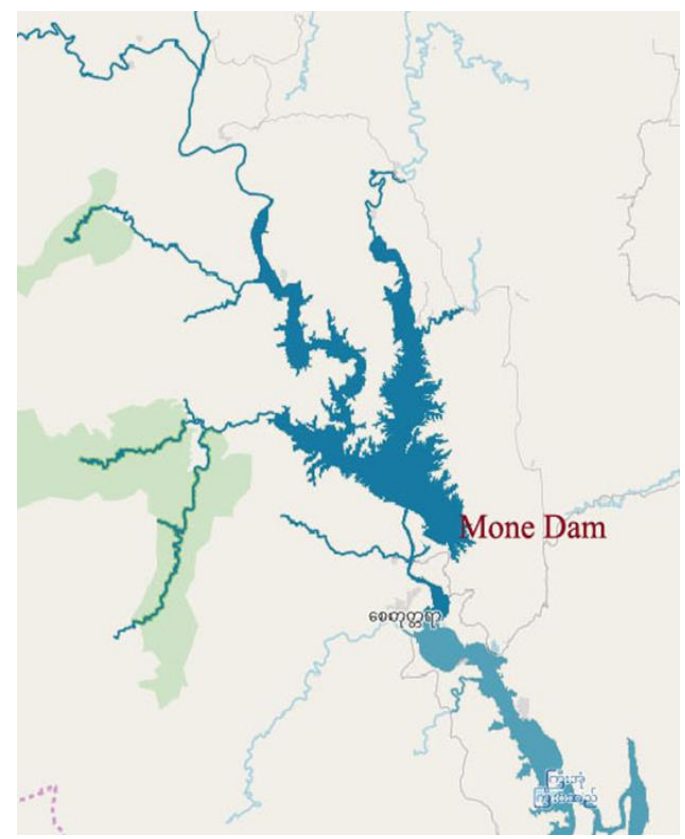

(b)

Fig. 1(a). shows the map of location of Mone, Fig. 1(b): shows the map of inflow water of Mone dam

The monsoon rain, storm and cyclone in Bay-of-Bengal and unconditional rain in Chin and Rakhine Hill in Myanmar may be caused flooding in this area. People who live in downstream area are very affected on flood when the dam cause flood or over flow water from dam. Fig 2 shows the map of downstream area of the dam. 

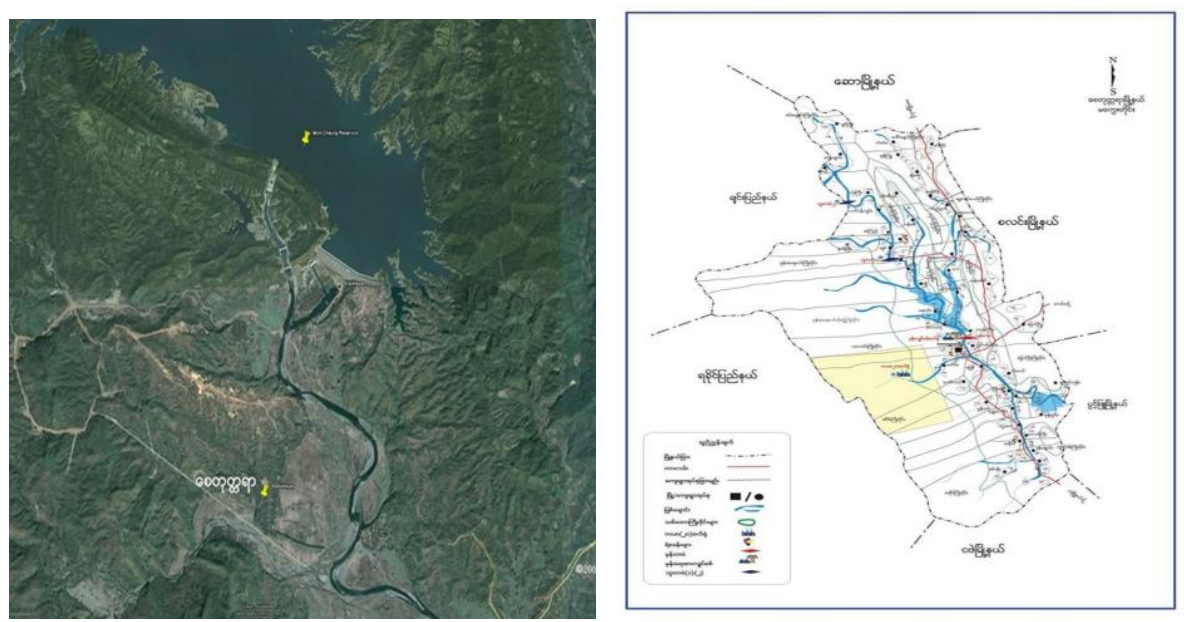

Fig. 2: Affected flood region of Mone Dam

The rain were exceptionally heavy, in the mountains of the country's central and northern regions, rainfall levels and river discharge rate reached unprecedented levels. The follow ing table shows the overflow water level of Mone Dam.

Table 1. Overflow condition of mone dam

\begin{tabular}{|c|c|c|c|}
\hline Year & $\begin{array}{c}\text { Water level } \\
(\mathrm{ft})\end{array}$ & $\begin{array}{c}\text { Overflow water } \\
(\mathrm{ft})\end{array}$ & $\begin{array}{c}\text { Overflow Capacity } \\
\text { (cu.ft/s) }\end{array}$ \\
\hline 2010 & RL 540.30 & 20.30 & 99,200 \\
\hline 2011 & RL 536.30 & 16.30 & 71,400 \\
\hline 2015 & RL 535.90 & 15.90 & 66,800 \\
\hline
\end{tabular}

\section{Markov Chain}

Markov Chain is stochastic process (random process) that include random variable $\left\{X_{0}, X_{1}, \ldots, X_{n}\right\}: X_{t}$ is described the state of the system at time t. Markov Chain is conditionally independent of all the other preceding random variables. Figure 3 shows the process of Markov Chain.

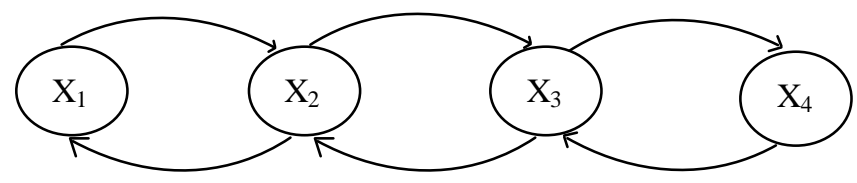

Fig. 3: Markov Chain Process

The finite state $\mathrm{N}$ is $\mathrm{S}$ that is equal to $\{1,2,3, \ldots, N\}$ and the value of random variable $X_{t}$ are taken from $S$. $\mathrm{N}$ refers to the length of $\mathrm{S}$ and $\mathrm{P}$ refers to $\mathrm{N} \times \mathrm{N}$ marix. The conditional probability $\mathrm{p} \operatorname{Pr}\left(\mathrm{x}_{+1} \mid \mathrm{x}_{\mathrm{n}}\right)$ only depends on the current state and the mathematical formula describes as follow:

$$
\operatorname{Pr}\left(\mathrm{X}_{\mathrm{n}+1}=\mathrm{X}_{\mathrm{n}+1} \mid \mathrm{X}_{\mathrm{n}}=\mathrm{X}_{\mathrm{n}}, \mathrm{X}_{\mathrm{n}-1}=\mathrm{X}_{\mathrm{n}-1, \ldots,} \mathrm{X}_{1}=\mathrm{x}_{1}\right)=\operatorname{Pr}\left(\mathrm{X}_{\mathrm{n}+1}=\mathrm{X}_{\mathrm{n}+1} \mid \mathrm{X}_{\mathrm{n}}=\mathrm{X}_{\mathrm{n}}\right)
$$

for all $\mathrm{x}_{1}, \mathrm{x}_{2}, \ldots, \mathrm{x}_{\mathrm{n}}, \mathrm{x}_{\mathrm{n}+1} \in \chi$

\subsection{Weather API}

In this work, weather data get from weather API ('Powered by Dark Sky API). It is allowed to use their weather data anywhere on the globe. It provides current weather conditions as minute-by-minute, hours-byhours etc... There are two types API requests to retrieve the weather data.

- Forest request: returns current weather conditions

- Time Machine Request: observed in the past or forecast in the future.

To use weather API, the user used need to create account and login to get secret key. Latitude and longitude also required to know the location that the weather data get where the user wants to know location and time to return request. 


\subsection{Two-state and three-state Markov Chain}

This study uses two two-state Markov Chain and three three-state Markov Chain. First, two-state Markov Chain is needed for knowing storm conditions if storm occur or not represent ' $\mathrm{Y}$ ' for 'yes' and ' $\mathrm{N}$ ' for 'not'. Second, it is required determine the outlet can emit or not where ' 1 ' stands for 'emit' and ' 0 ' stands for 'not emit'.

The transition probabilities matrix of two-state (Y-N and 1-0) Markov Chain is as follow:

$$
\mathrm{P}=\left(\begin{array}{ll}
S_{Y Y} & S_{Y N} \\
S_{N Y} & S_{W N}
\end{array}\right) \quad \mathrm{P}=\left(\begin{array}{ll}
O_{11} & O_{10} \\
O_{01} & O_{00}
\end{array}\right)
$$

In three-state Markov, first represent for rain conditions as no-rain, rain and heavy rain stands for 'NR', ' $R$ ' and ' $H R$ ' respectively. Second for water level to know about the water conditions as non-flood, flood and severe flood stands for 'NF', 'F' and 'SF' respectively.

There are some steps for flood prediction: First, it input water level data. Then check water level data to know about the level of water in dam and to calculate the conditions of flood by combining weather data where the data get from weather API. The database store the weather data get form dark sky API. There are some states to get real-time weather data from weather API. People need to sing up needed to use the resource of weather information from web page.

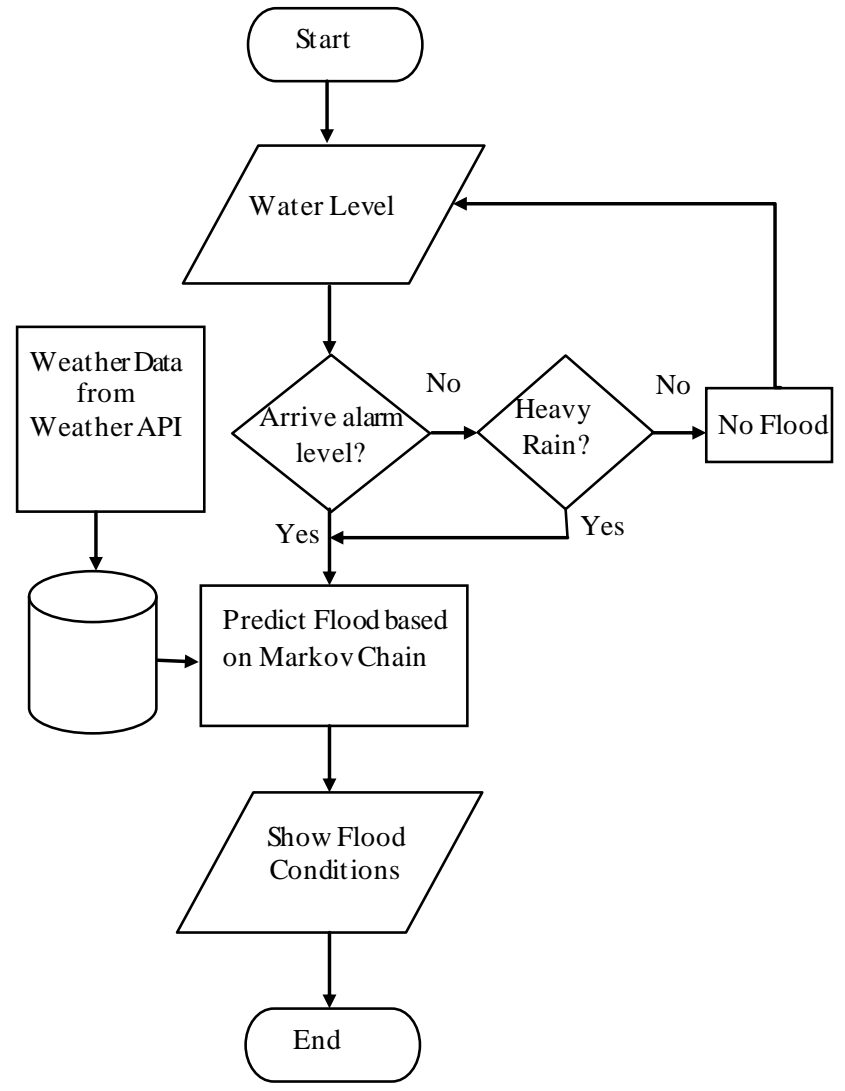

Fig. 4: System flow of Flood Prediction System.

After that this work combines the data and predict flood conditions based on Markov chain. And then, calculate standard deviation and set threshold according to standard deviation value to predict flood conditions. In this system, water level defines as "WL" compare with threshold value "T". The value of "T" defines as T1,T2, and T3 where 1 is No Flood (NF), 2 is Flood (F) and 3 is Severe Flood (SF). Finally, it will show the flood conditions according to threshold. If WL $<$ T1then flood condition is NF, If WL $>$ T2then flood condition is $\mathrm{F}$ and If $\mathrm{WL} \geq \mathrm{T} 3$ then flood condition is $\mathrm{SF}$. 


\section{Experimental Result}

In humans' society, flood is becoming the most affected hazard and it is needed to fend off flood. The bear reservoir level is 520 feet and 540 feet is alarm level. Dam creak level is very dangerous level for dam and arrived at 560 feet. The western and northern regions of country are full of mountain and if the rain were unconditionally heavy, creek discharge rate reached unprecedented level. The Mone dam's prediction result is shown in table 2:

Table 2.Overflow Prediction Results

\begin{tabular}{|c|l|c|c|c|}
\hline Date & Water level (ft) & Threshold value & Predict & Remark \\
\hline 12.6 .18 & RL 512.2 & 1 & NF & May still be raining and flood may be occur \\
\hline 13.6 .18 & RL 526.7 & 2 & F & Warning and may still be increase water \\
\hline 14.6 .18 & RL 537.9 & 3 & SF & Should move to safe places \\
\hline 17.6 .18 & RL 531.1 & 3 & SF & Still flood but will reduce water level \\
\hline
\end{tabular}

In this system, table (2) shows the result according to the threshold values. For example, RL 512.2 is less than bear reservoir level 520. So it is not occurred flood in this level and then predicts result shows NF (Not Flood). After that, RL 526.7 is greater than 520 feet and equal to threshold 2. So it is predicted F(Flood) etc..

\section{Conclusion}

Flood is one of the most affected disasters in the world. Flood prediction system is critical factor to controls prevent and reduce of damage from hazard. This work proposed to support the early warning system that it predicts the conditions of flood by using threshold values that are calculated based on weather conditions and reservoir water level. This work will help to inform people who live in low laying area of Mone dam to take precaution before meet the flood. Today, mobile phone is very popular devices and many people use it. Therefore, mobile device is one useful device to get alarm flood by using mobile apps and can avert from flood.

\section{References}

[1] Department of Meteorology and Hydrology, Myanmar's National Adaptation Programme of Action (NAPA) to Climate Change, Myanmar National Adaptation Programme of Action (NAPA), 2012.

[2] Hafzullah Aksoy, Division of Hydraulic, Civil Engineering Faculty, Technical University of Istanbul, Ayazaga 80626 Istanbul, Turkey, Markov chain-based modeling techniques for stochastic generation of daily intermittent stream flows, Advances in Water Resources 26 (2003) $663-671$

[3] Jayashree S, SarikaS, Solai A L, *Soma Prathibha, A Novel Arroach for Early Flood Warning using Android and IOT, 2017 Second International Conference On Computing and Communications Technologies (ICCCT'17)

[4] ParticeYapo, A Markov Chain Flow Model for Flood Forecasting, Water Resource Research, Vol.29, No.7, pages 2427-2436, July 1993.

[5] R.Kavith and Mr.S.Anuvelavan, Weather Master: Mobile Application of Cyclone Disaster Refinement Forecast System in Location Based on GIS Using Geo-Algorithm, International Journal of Scientific \& Engineering Research, Volume 6, Issue 4, April-2015.

[6] T. C. Cham, Y. Mitani, K. Fujii \& H. Ikemi, Graduate School of Civil and Structural Engineering, Kyushu University, Japan, Evaluation of flood volu me and inundation depth by GIS midstream of Chao Phraya River Basin, Thailand, WIT Transactions on The Built Environment, Vol 168, (C) 2015 WIT Press. 